\title{
Global DNA methylation and increased DNMT3A expression in multiple myeloma patients
}

\author{
Petra Luzna' ', Denisa Weiser Drozdkova' , Pavla Flodrova' ', Katarina Ondruskova' ', Ivo Uberall', Jiri Minarik², , Zdenek Kolar1', \\ Katerina Smesny Trtkova ${ }^{1,4}$
}

\begin{abstract}
Aims. The aim of this study was to compare the expression profile of selected DNA methyltransferases and global DNA methylation status in patients with different phases of multiple myeloma (MM) . For the analysis, different cellular populations including unsorted myeloma cells and a set of plasma cells purified by relevant antibodies were used. Consequently, laboratory data were compared to patients' clinical data.

Patients and Methods. For the analysis, unsorted bone marrow cell population of $44 \mathrm{MM}$ patients ( 30 newly diagnosed, 9 relapsed and 5 patients in remission) and a set of 8 patients' samples of sorted plasma cells were used. We used commercially available RNA isolated from BM of 3 healthy individuals as control samples. Expression analysis of three DNA methyltransferases - DNMT1, DNMT3A, and DNMT3B was performed by quantitative RT-PCR and the patient global DNA methylation profiles were detected by colorimetric assay.

Results. Unchanged DNMT1 expression was detected in the selected cohort of patients. Normalized DNMT3A gene expression was globally higher in comparison with controls in unsorted and sorted cell populations. Low (0.08-1.81\%) global DNA methylation status in unsorted samples of multiple myeloma patients did not correlate either with expression profiles of monitored DNA methyltransferases or with the stages of MM based on Durie-Salmon and International Staging System.

Conclusion. This is the first comparative study between DNA methyltransferases expression profiles and global DNA methylation status in different phases of multiple myeloma patients. No significant correlation between the level of global methylation and the clinical stage of the unsorted cell population of patients with multiple myeloma was registered. Overexpression of the DNMT3A gene occurred in both sorted and unsorted cell populations of patients with multiple myeloma. This fact highlights the DNMT3A as a potential marker of multiple myeloma tumor progression. Moreover, we demonstrated comparable results in the expression of DNA methyltransferases in both sorted and unsorted cell populations. This is a promising result from the methodical point of view because when compared to samples of unsorted multiple myeloma cells, samples of sorted cells bring reduction of the number of possible analyses performed.
\end{abstract}

Key words: multiple myeloma, DNA methyltransferases, DNA methylation

Received: January 19, 2022; Revised: January 19, 2022; Accepted: February 2, 2022; Available online: February 16, 2022 https://doi.org/10.5507/bp.2022.006

(c) 2023 The Authors; https://creativecommons.org/licenses/by/4.0/

'Department of Clinical and Molecular Pathology, Faculty of Medicine and Dentistry, Palacky University Olomouc, Czech Republic ${ }^{2}$ Department of Hemato-Oncology, University Hospital Olomouc, Czech Republic

${ }^{3}$ Department of Hemato-Oncology, Faculty of Medicine and Dentistry, Palacky University Olomouc, Czech Republic

${ }^{4}$ Institute of Molecular and Translational Medicine, Faculty of Medicine and Dentistry, Palacky University Olomouc, Czech Republic Corresponding author: Petra Luzna, email:petra.Iuzna@seznam.cz; Katerina Smesny Trtkova, email: katerina.smesny@upol.cz

\section{INTRODUCTION}

Multiple myeloma (MM) is a clonal malignancy characterized by proliferation of plasma cells in bone marrow ${ }^{1}$. It starts as an asymptomatic monoclonal gammopathy of undetermined significance (MGUS), but this stage is not necessarily detected in all patients. $1 \%$ of MGUS patients progress to symptomatic MM per each year ${ }^{2}$. Despite novel therapeutic agents and strategies, MM is still considered to be an incurable disease ${ }^{3.8}$.

In 1975, a system for determining the clinical stage of MM based on the classification of Durie and Salmon (D-S) was introduced. It is still a well-applicable system. MM is divided into stages I-III based on given criteria (concentration of hemoglobin, calcium or monoclonal immunoglobulin, skeletal damage, etc.) reflecting the extent of the tumor mass in the body and the progression of the disease. Subclassification (A/B) is based on the level of creatinine. International Staging System (ISS), the international prognostic system for multiple myeloma that has been used since 2003, is easier than Durie and Salmon's classification, using only 2 laboratory indicators to determine prognosis: serum albumin and beta2-microglobulin. In 2015, ISS system was revised (R-ISS) and the prognostic system was expanded by 2 new indicators: LDH concentrations and the presence of risky cytogenetic changes del $(17 \mathrm{p})$ and/or translocation $\mathrm{t}(4 ; 14)$ and/ or translocation $\mathrm{t}(14 ; 16)$ (ref. ${ }^{9}$ ).

Abnormal gene hypermethylation accompanied by global DNA hypomethylation are changes generally seen 
in human cancer. There is evidence that global DNA hypomethylation may result in chromosomal instability. As shown in previous studies ${ }^{10,11}$, apart from chromosomal gains or losses, translocations and cancer driver mutations typically seen in the MM genomic landscape, epigenetic anomalies have been identified as important drivers in MM development. DNA methylation is one of the posttranslational/epigenetic modifications that can affect a gene's function. The addition of methyl group to cytosine in DNA is catalyzed by so-called DNA methyltransferases - DNMT1, DNMT3A, DNMT3B, which cause its modification to 5-methylcytosine. Hypermethylation of tumor suppressor gene promoters may lead to gene expression inhibition thus contributing to tumor formation ${ }^{12-15}$.

The aim of our study was to perform pilot assessment of DNA methyltransferases expression profiles and global DNA methylation status in bone marrow samples of multiple myeloma patients.

\section{MATERIALS AND METHODS}

\section{Unsorted cell population of multiple myeloma patients}

We analysed unsorted cell population of bone marrow aspirates of 44 multiple myeloma patients at different phases of MM The analyzed group of patients consisted of 30 newly diagnosed multiple myeloma patients, 9 patients in relapse, and 5 in remission of the disease. Altogether, there were 19 men and 25 women, with median age 68 years. The diagnosis of MM was guided by International Myeloma Working Group criteria ${ }^{16}$. The basic characteristics of the cohort are summarized in Table 2. The study was approved by the Ethics Committee of the Olomouc University Hospital and all samples were taken after informed consent.

\section{Cluster of differentiation (CD) purified plasma cells}

Purified plasma cells of 8 multiple myeloma patients were analyzed, all in active phase of the disease, 5 newly diagnosed and 3 in relapse, Table 2 Plasma cells (PCs) were separated from bone marrow aspirate of MM patients by Histopaque-1077 medium (Histopaque ${ }^{\circledR}-1077$, Sigma Aldrich, St. Louis, Missouri, USA) according to the manufacturer's instructions. Centrifugation on ficoll gradient was used to isolate total lymphocytes from the sample, then the obtained lymphocytes were incubated with a set of the following antibodies: Anti-Human CD 19+ (Beckman Coulter Life Science, Indianapolis, Indiana, USA), FITC Anti-Human CD38+ (Immunostep, Salamanca, Spain), Anti-Human CD45 (Agilent Dako, Santa Clara, California, USA), and Anti-Human CD56 ${ }^{+}$ (Agilent Dako, Santa Clara, California, USA), and sorted by flow cytometry.

\section{Nucleic Acid Isolation}

Total RNA was isolated from an unsorted bone marrow population using TRI Reagent ${ }^{\circ}$ BD (Molecular Research Center, Inc., OH, USA) according to the manufacturer's protocol.
Total RNA from purified plasma cells was isolated by Norgen Single Cell RNA Purification Kit (Norgen Biotek Corp, Thorold, ON, Canada) according to the manufacturer's instructions.

Genomic DNA was isolated from an unsorted bone marrow cell population using the QIAamp DNA Mini Kit (Qiagen, Hilden, Germany). Both the RNA and DNA concentration and purity were measured using a nanodrop (NanoDrop ND-1000, Thermo Fisher Scientific) instrument.

\section{Expression analysis of DNA methyltransferases (DNMTs)}

100 ng of total RNA was converted by reverse transcription into cDNA using the Transcriptor First Strand cDNA Synthesis Kit (Roche, Basel, Switzerland) according to the manufacturer's instructions. cDNA was used for the expression analysis of DNA methyltransferase (DNMT1, DNMT3A, DNMT3B) expression. RNA isolated from a sorted population of bone marrow cells was transcribed into cDNA via EasyScript Plus cDNA Synthesis Kit (Applied Biological Material, Inc., Richmond, Canada).

The qRT-PCR with TaqMan and Xceed qPCR Probe Mix probes (Institute of Applied Biotechnologies, Prague, Czech Republic) was performed using the Light cycler ${ }^{\circledR} 480$ system (Roche, Basel, Switzerland). The expression of DNMTs was normalized to the endogenous house-keeping control, the GAPDH gene. All probes were provided by Thermo Fisher Scientific (Waltham, MA, USA). Commercially available RNA isolated from BM of 3 healthy individuals (Takara Bio USA, Inc., Mountain View, CA, USA) was used as the calibrator for $2^{-\Delta \Delta C t}$ quantification.

\section{Colorimetric analysis of global DNA methylation}

Isolated DNA was used for colorimetric detection of global methylation (\% 5-mC) using the MethylFlash ${ }^{\mathrm{TM}}$ Methylated DNA Quantification Kit (Epigentek, Farmingdale, NY, USA). The method is based on the binding of genomic DNA (approx. $100 \mathrm{ng}$ ) to the specially modified bottom of a 96-well plate (part of the kit). After DNA binding, the sample was washed and a primary antibody which binds to the methylated DNA was applied. After binding of the secondary antibody followed by adding an enhancer, a colorimetric reaction occurred, and the absorbance at $450 \mathrm{~nm}$ was measured. The experiment was performed in triplicates, negative control was included. 5 different known concentrations of methylated DNA were used to generate a calibration curve. The level of global methylation was calculated as follows: 5-mC (ng) $=($ absorbance of the sample - absorbance of the negative control $) /$ slope $^{*} \times 2$; $5-\mathrm{mC} \%=(5-\mathrm{mC}$ in $\mathrm{ng} / \mathrm{S} *) \times 100 \%$ (5-mC $=5$-methylcytosine, $\mathrm{S}$ is the amount of DNA in the reaction, the slope value is obtained from the linear regression).

\section{Statistical analysis}

The data were analyzed using two non-parametrical tests, Spearman rank-correlation coefficient and 


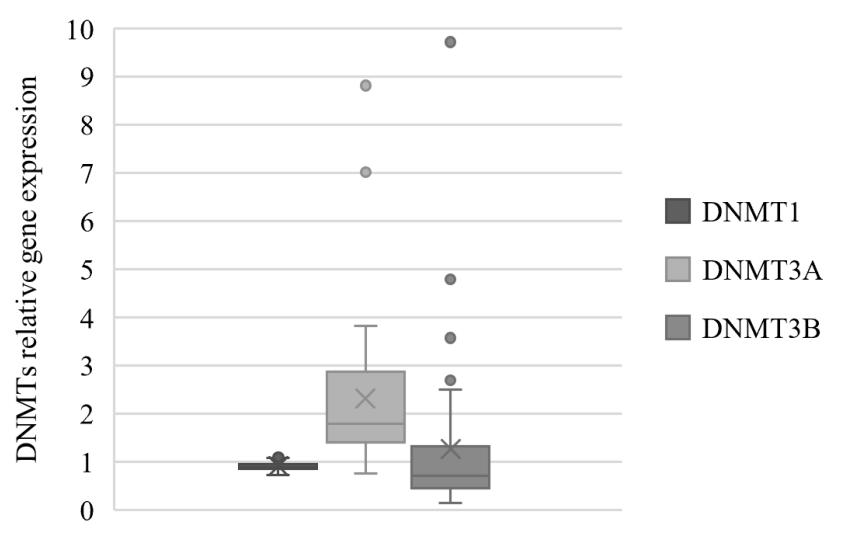

Fig. 1. Comparison of DNMT1, DNMT3A and DNMT3B expression profile detected in unsorted cell samples obtained from 44 multiple myeloma patients.

Kruskal-Wallis test. Statistically significant differences are marked with an asterisk $(*)$ directly in the text or in the tables $(* P \leq 0.05)$.

\section{RESULTS}

\section{Expression profiles of DNA methyltransferases}

For the expression analysis, we used the whole cohort of unsorted cell samples of all 44 multiple myeloma patients. Furthermore, a set of 8 samples of purified plasma cells from 5 newly diagnosed multiple myeloma patients and 3 patients in relapse were obtained.

In the set of the unsorted patients' samples, we analysed the levels of the expression of the methyltransferases with respect to the healthy controls. The final outcomes are therefore presented in relative expression levels. The levels of DNMT1 and DNMT3B were comparable to the controls, however, an increased DNMT3A expression was detected, moreover even in comparison with DNMT1 and DNMT3B expression profiles (Fig. 1) (average relative DNMT3A expression $=2.2 ;$ DNMT1 $=0.9 ;$ DNMT3B $=$ 1.4 , respectively).

Similar results with higher DNA methyltransferase expression was observed in both the unsorted and the sorted cell population of multiple myeloma patients. In both sorted and unsorted cell populations, an increased level of relative expression of the DNMT3A gene was detected when compared to DNMT1 and DNMT3B expressions (Fig. 5A, 5B).

As we had samples from 3 different phases of MM (remission phase, diagnosis and relapse), we tried to compare the expression profiles of all the three methyltransferases within these phases. We didn't find any statistically significant differences in DNMT1 nor DNMT3B expression profile in any of the analysed subset of patients (Table 1, Fig. 2, 4). Nevertheless, we could observe a trend towards higher expression levels of DNMT3A in active phase of MM (newly diagnosed and relapsed) versus the remission phase of the disease (Fig. 3).

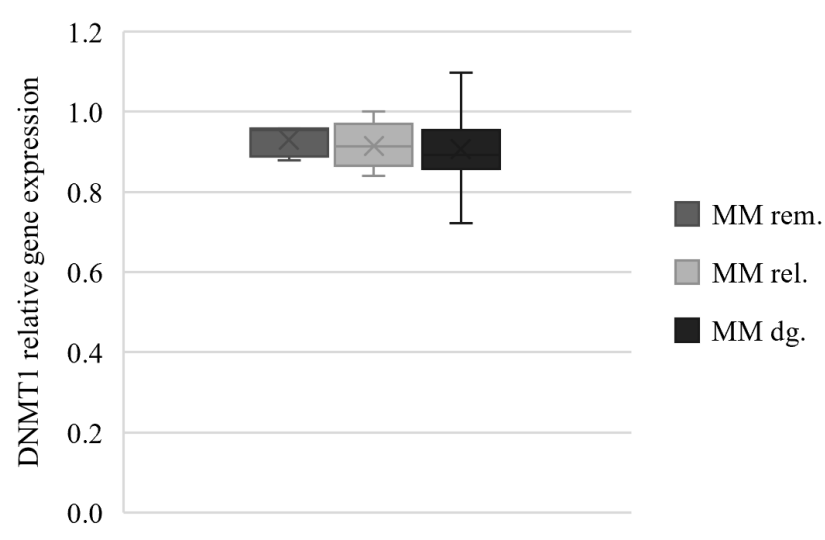

Fig. 2. Relative DNMT1 expression detected in unsorted cell samples of three subgroups of MM patients.

MMdg. - newly diagnosed MM, MMrel. - MM in relapse, and MMrem. - MM in remission

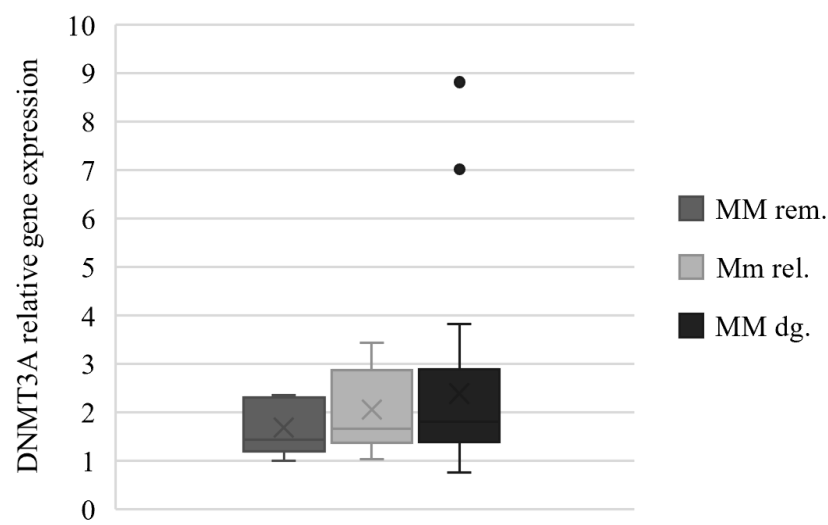

Fig. 3. Relative DNMT3A expression detected in unsorted cell samples of three subgroups of MM patients.

MMdg. - newly diagnosed MM, MMrel. - MM in relapse, and MMrem. - MM in remission

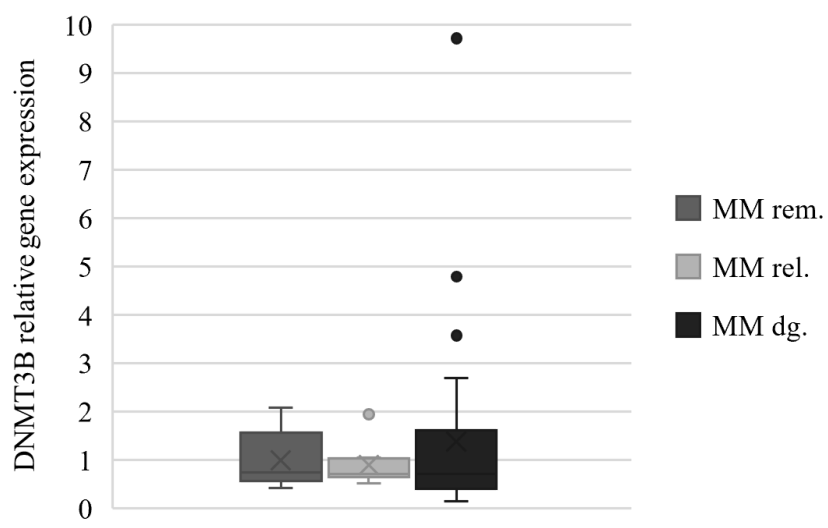

Fig. 4. Relative DNMT3B expression detected in unsorted cell samples of three subgroups of MM patients.

MMdg. - newly diagnosed MM, MMrel. - MM in relapse, and MMrem. - MM in remission 

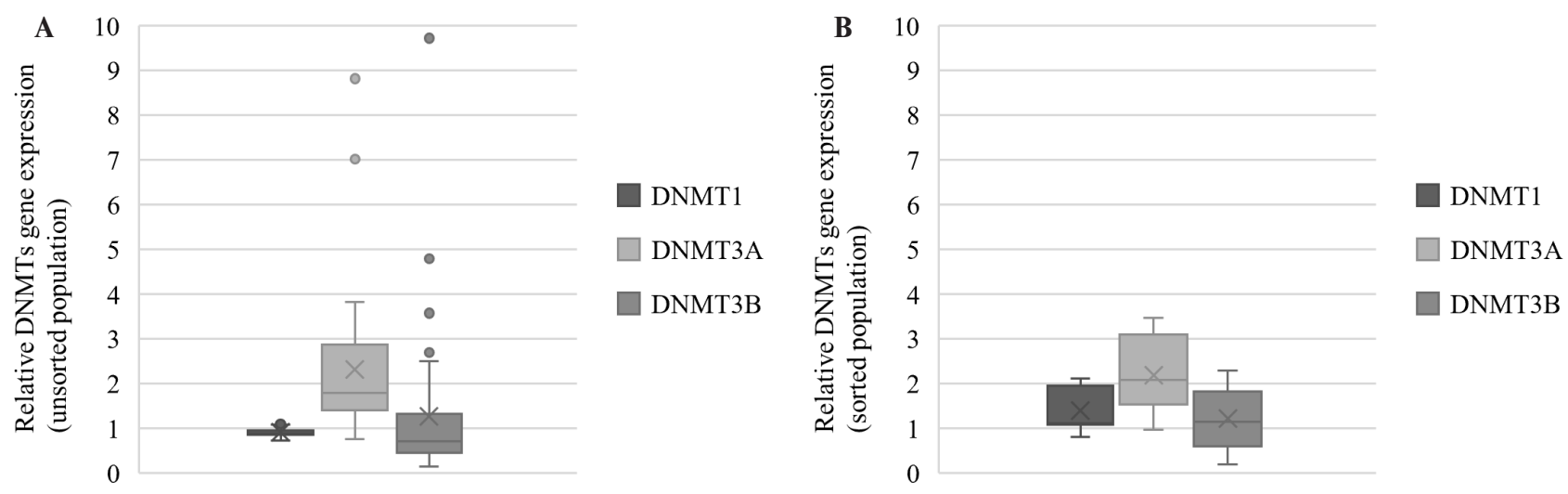

Fig. 5. Comparison of DNMT1, DNMT3A and DNMT3B gene expression profile in samples of unsorted cell populations (39 patients). A. and purified plasma cells (8 patients). B. obtained from newly diagnosed MM patients (MMdg.) and patients in relapse (MMrel.)

Table 1. Statistical analysis of DNMTs expression levels detected in samples of unsorted cell populations among three subgroups of MM patients.

\begin{tabular}{lc}
\hline Gene & $P$ \\
\hline DNMT1 & 0.5182 \\
DNMT3A & 0.6357 \\
DNMT3B & 0.8149 \\
\hline
\end{tabular}

MMdg. - newly diagnosed MM, MMrel. - MM in relapse, and MMrem. - MM in remission

\section{Global DNA methylation in unsorted cell samples}

Our next aim was to determine the global DNA methylation level in different phases of the development of multiple myeloma. We proceeded to determine the global DNA methylation in the whole set of 44 patient samples. Although the physiological value of global cytosine methylation was reported to be about $4 \%\left(\right.$ ref. $\left.{ }^{17}\right)$, the global DNA methylation in our set of multiple myeloma patients varied in the range from 0.08 to $1.81 \%$. Statistical analysis of global DNA methylation percentage values among monitored subgroups of MM patients showed no significant difference among the groups $(P=0.1088)$ (Fig. 6). However, similarly as in the case of DNMT3A, there was a trend towards different (lower) levels of global methylation in remission phase $\mathrm{MM}$ with respect to both newly diagnosed and relapsed patients.

\section{Correlation of methylation profiles and clinical stages of multiple myeloma}

We finally tried to compare the expression profiles of all the three selected methyltransferases (DNMT1, DNMT3A, DNMT3B) with respect to the global DNA methylation. Having the data on individual D-S and ISS stages of multiple myeloma, we performed a correlation analysis of the methylation status with respect to the clinical stages. In the unsorted cell samples, we did not detect any statistically significant correlation between the global

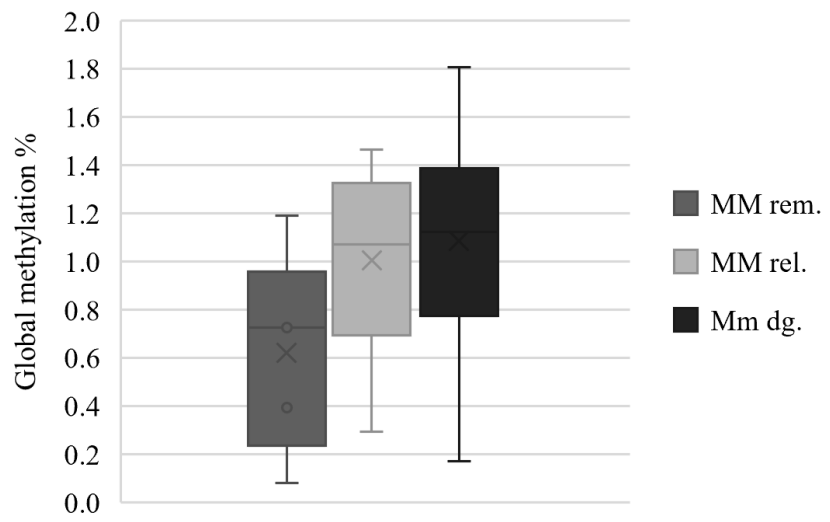

Fig. 6. Comparison of global DNA methylation (\%) among three subgroups of MM patients (unsorted samples).

MM dg. - newly diagnosed MM, MMrel. - MM in relapse, and MM rem. - MM in remission

DNA methylation status and either D-S or ISS stage of multiple myeloma (Table 3 ). There was also no statistically significant relationship between the global DNA methylation and DNA methyltransferases (DNMT1, DNMT3A, DNMT3B) expression (Table 4).

\section{DISCUSSION}

DNMT3A and DNMT3B catalyze de novo DNA methylation, while DNMT1, which is called a maintenance methyltransferase, preferentially catalyzes hemi-methylation of DNA after each cell division. Gene transcription silencing does not have to be permanent, recent studies describe the possibility of 5-methylcytosine demethylation. That is why epigenetic modifications, including DNA methylation, could be an attractive target for potential cancer treatment. In some types of cancer, hypomethylation agents can restore desirable physiological processes, such as DNA repair, or contribute to cancer cell apopto$\operatorname{sis}^{15,18}$. So far, the cause of unusual DNA methylation in 
Table 2. MM patients' characteristics.

\begin{tabular}{|c|c|c|c|c|c|c|c|c|c|}
\hline \multirow{2}{*}{ 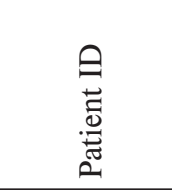 } & \multirow{2}{*}{ 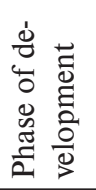 } & \multirow[b]{2}{*}{ 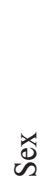 } & \multirow{2}{*}{ 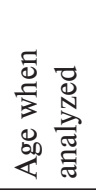 } & \multicolumn{3}{|c|}{ Rel.gene expression } & \multirow{2}{*}{ 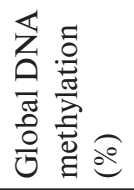 } & \multirow{2}{*}{ 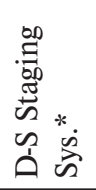 } & \multirow{2}{*}{ 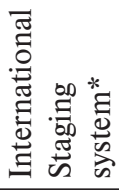 } \\
\hline & & & & DNMT1 & DNMT3A & DNMT3B & & & \\
\hline \multicolumn{10}{|c|}{ UNSORTED POPULATION } \\
\hline M58 & rem & $\mathrm{F}$ & 56 & 0.9580 & 2.3590 & 1.0420 & 0.0800 & III A & 3 \\
\hline M55 & rem & $\mathrm{F}$ & 67 & 0.9560 & 1.0070 & 0.41900 & 0.3930 & III A & 2 \\
\hline M66 & rem & $\mathrm{F}$ & 63 & 0.8980 & 1.4340 & 0.7070 & 0.7250 & II A & 1 \\
\hline M65 & rem & M & 60 & 0.8790 & 1.3850 & 0.7500 & 0.7250 & II A & 1 \\
\hline M80 & rem & M & 65 & 0.9540 & 2.2660 & 2.0780 & 1.1890 & III B & 3 \\
\hline M57 & rel & $\mathrm{F}$ & 73 & 0.8800 & 1.6210 & 0.7000 & 0.2930 & II A & 2 \\
\hline M61 & rel & $\mathrm{F}$ & 74 & 0.9360 & 2.2420 & 0.6710 & 0.5890 & II A & 1 \\
\hline M28 & rel & $\mathrm{F}$ & 72 & 0.8530 & 1.0280 & 0.5210 & 0.8000 & II A & 1 \\
\hline M84 & rel & $\mathrm{F}$ & 65 & 0.9910 & 1.5490 & 1.0470 & 0.9930 & II A & 1 \\
\hline M39 & rel & $\mathrm{F}$ & 64 & 0.8770 & 2.6030 & 0.7790 & 1.0720 & III A & 1 \\
\hline M37 & rel & M & 69 & 0.9460 & 1.6590 & 0.7170 & 1.1740 & II A & 1 \\
\hline M33 & rel & M & 68 & 1.0000 & 3.1490 & 0.6350 & 1.4310 & II A & 1 \\
\hline M30 & rel & M & 57 & 0.9140 & 3.4340 & 1.9450 & 1.4630 & III A & 2 \\
\hline M83 & rel & M & 71 & 0.8390 & 1.1810 & 1.0140 & 1.2200 & III B & 3 \\
\hline M86 & $\mathrm{dg}$ & M & 68 & 0.9590 & 1.7840 & 1.6530 & 0.5460 & III A & 2 \\
\hline M56 & $\mathrm{dg}$ & $\mathrm{F}$ & 41 & 0.8550 & 1.6660 & 0.1470 & 0.4050 & III A & 2 \\
\hline M25 & $\mathrm{dg}$ & $\mathrm{F}$ & 58 & 0.8950 & 1.4040 & 0.4090 & 0.6430 & III B & 3 \\
\hline M50 & $\mathrm{dg}$ & M & 68 & 0.8590 & 1.404 & 1.2100 & 0.1720 & III A & 2 \\
\hline M64 & $\mathrm{dg}$ & M & 61 & 0.9660 & 1.2060 & 2.6940 & 0.2730 & IIA & 2 \\
\hline M10 & $\mathrm{dg}$ & M & 75 & 0.8170 & 2.1990 & 0.3010 & 0.7420 & III B & 3 \\
\hline M68 & $\mathrm{dg}$ & M & 78 & 0.9200 & 2.0350 & 1.3240 & 0.7450 & III A & 2 \\
\hline M79 & $\mathrm{dg}$ & M & 67 & 0.8800 & 2.9720 & 2.5050 & 0.7850 & II A & 1 \\
\hline M08 & $\mathrm{dg}$ & M & 62 & 0.8460 & 1.3200 & 0.4560 & 0.9770 & II A & 1 \\
\hline M26 & $\mathrm{dg}$ & $\mathrm{F}$ & 75 & 0.8890 & 1.8400 & 0.7120 & 0.9900 & III A & 2 \\
\hline M02 & $\mathrm{dg}$ & $\mathrm{F}$ & 68 & 1.0830 & 2.3700 & 0.3310 & 0.9980 & III A & 3 \\
\hline M36 & $\mathrm{dg}$ & $\mathrm{F}$ & 74 & 0.7220 & 8.8150 & 4.7900 & 1.0180 & II A & 2 \\
\hline M21 & $\mathrm{dg}$ & $\mathrm{F}$ & 79 & 0.9140 & 2.8680 & 0.5010 & 1.0540 & III A & 3 \\
\hline M04 & $\mathrm{dg}$ & M & 73 & 1.0870 & 2.8280 & 0.4730 & 1.1160 & III B & 3 \\
\hline M81 & $\mathrm{dg}$ & $\mathrm{F}$ & 71 & 0.8830 & 3.4500 & 9.7140 & 1.1180 & III A & 2 \\
\hline M27 & $\mathrm{dg}$ & M & 70 & 0.8770 & 1.3290 & 0.8350 & 1.1270 & III A & 2 \\
\hline M69 & $\mathrm{dg}$ & $\mathrm{F}$ & 72 & 0.8880 & 2.2290 & 1.0090 & 1.1270 & A & 2 \\
\hline M78 & $\mathrm{dg}$ & $\mathrm{F}$ & 80 & 0.9120 & 7.0130 & 1.6040 & 1.1400 & II A & 1 \\
\hline M77 & dg & $\mathrm{F}$ & 73 & 0.7870 & 1.4900 & 0.6200 & 1.1850 & III A & 2 \\
\hline M24 & $\mathrm{dg}$ & $\mathrm{F}$ & 63 & 0.8710 & 1.6020 & 1.1410 & 1.2310 & IIII A & 3 \\
\hline M62 & $\mathrm{dg}$ & $\mathrm{F}$ & 64 & 0.9440 & 0.8790 & 0.3300 & 1.3010 & III A & 1 \\
\hline M03 & $\mathrm{dg}$ & $\mathrm{F}$ & 68 & 0.9230 & 1.3240 & 0.6950 & 1.3400 & III B & 3 \\
\hline M85 & $\mathrm{dg}$ & M & 82 & 0.8320 & 3.8150 & 0.8040 & 1.3840 & III A & 3 \\
\hline M06 & $\mathrm{dg}$ & $\mathrm{F}$ & 63 & 0.9940 & 0.7530 & 0.3910 & 1.3900 & III A & 2 \\
\hline M07 & $\mathrm{dg}$ & $\mathrm{F}$ & 71 & 1.0970 & 2.9490 & 1.6250 & 1.4170 & II A & 3 \\
\hline M12 & $\mathrm{dg}$ & M & 68 & 0.8180 & 2.6210 & 0.3760 & 1.5250 & I A & 1 \\
\hline M38 & $\mathrm{dg}$ & $\mathrm{F}$ & 51 & 0.8950 & 1.2570 & 0.4510 & 1.5300 & III A & 2 \\
\hline M20 & $\mathrm{dg}$ & M & 71 & 0.9530 & 1.5480 & 0.4150 & 1.6880 & III B & 2 \\
\hline M70 & $\mathrm{dg}$ & $\mathrm{F}$ & 68 & 0.9560 & 2.9320 & 0.1640 & 1.7740 & III B & 3 \\
\hline M29 & $\mathrm{dg}$ & M & 87 & 0.8590 & 1.6930 & 3.5680 & 1.8050 & II A & 2 \\
\hline \multicolumn{10}{|c|}{ SORTED POPULATION } \\
\hline 20200107 & rel & $\mathrm{F}$ & 60 & 1.1171 & 1.5119 & 0.7262 & $\mathrm{x}$ & II A & 1 \\
\hline 20200120 & rel & M & 70 & 1.8969 & 1.8462 & 2.2831 & $\mathrm{x}$ & III B & 3 \\
\hline 20191118B & rel & $\mathrm{F}$ & 74 & 1.9783 & 3.4715 & 1.8292 & $\mathrm{x}$ & III A & 3 \\
\hline 20200304B & $\mathrm{dg}$ & $\mathrm{F}$ & 62 & 0.8014 & 2.3251 & 1.1541 & $\mathrm{x}$ & I A & 2 \\
\hline 20200225 & $\mathrm{dg}$ & $\mathrm{F}$ & 60 & 1.0788 & 3.3247 & 1.8214 & $\mathrm{x}$ & II A & 2 \\
\hline 20200330 & $\mathrm{dg}$ & M & 78 & 1.1083 & 1.5696 & 0.5572 & $\mathrm{x}$ & III A & 2 \\
\hline $20200629 C$ & $\mathrm{dg}$ & $\mathrm{F}$ & 63 & 1.1232 & 0.9648 & 0.1975 & $\mathrm{x}$ & II A & 1 \\
\hline 20200730 & dg & $\mathrm{M}$ & 75 & 2.1166 & 2.4310 & 1.1346 & $\mathrm{x}$ & III A & 2 \\
\hline
\end{tabular}

M - male, F - female, Dg. - newly diagnosed MM patient, rel - relapsed patient, rem - patients in remission, A - creatinine < 177 mmol/L, B - creatinine $>177 \mu \mathrm{mol} / \mathrm{L}, \mathrm{x}$ - global methylation level could not be due to low level of isolated DNA detected

*assessed at the time of MM diagnosis 
Table 3. Statistical analysis of global DNA methylation detected in unsorted samples of MM patients analyzed by prognostic scoring systems (Spearman rank-correlation coefficient).

\begin{tabular}{ll}
\hline Correlated data & Results \\
\hline Global DNA methylation vs. Durie-Salmon Staging System & $\mathrm{r}=0.1416, P=0.3593$ (ns) \\
Global DNA methylation vs. Durie-Salmon Staging System, subtype A or B & $\mathrm{r}=0.2149, P=0.1564$ (ns) \\
Global DNA methylation vs. International Staging System & $\mathrm{r}=0.1036, P=0.4984$ (ns) \\
\hline
\end{tabular}

(ns) - not significant

Table 4. Statistical analysis of global DNA methylation status and DNA methyltransferases expression in unsorted samples of MM patients.

\begin{tabular}{ll}
\hline Correlated data & Results \\
\hline DNMT1 expression vs. global methylation level & $\mathrm{r}=0.038, P=0.808(\mathrm{~ns})$ \\
DNMT3A expression vs. global methylation level & $\mathrm{r}=0.184, P=0.232(\mathrm{~ns})$ \\
DNM3B expression vs. global methylation level & $\mathrm{r}=-0.068, P=0.663(\mathrm{~ns})$ \\
\hline
\end{tabular}

(ns) - not significant

patients with MM is still unknown. Two scientific groups describe increased expression of DNMT1 in plasma cells of multiple myeloma patients compared to healthy individuals, and moreover the increase correlates with disease progression $^{15,19}$. However, it is not known whether the elevated expression of DNA methyltransferases causes global DNA methylation enhancement or is only the indicator of increased cell proliferation. Dimopulos et al. described decreased DNMT3A expression in multiple myeloma patients ${ }^{15}$ and Heuck et al. demonstrated hypermethylation of the DNMT3A gene promoter ${ }^{20}$.

About $4 \%$ of cytosine residues in the human genome have been found to be methylated ${ }^{17}$. It is known that DNA hypomethylation is associated with cancer and affects more of the genome than hypermethylation ${ }^{21}$. Some studies suggest that the level of global methylation could serve as an independent prognostic factor ${ }^{22,23}$. The possibility that the level of global methylation in multiple myeloma could serve as an independent prognostic factor has not yet been described in the literature. Moreaux and colleagues described the relationship between DNA methylation score of myeloma cells and sensitivity to hypomethylation treatment by 5 -azacytidine ${ }^{24}$.

In this study we describe the level of methylation and/ or expression changes of selected DNA methyltransferases in both unsorted and sorted bone marrow aspirates of multiple myeloma patients. Despite of the fact that we did not find any significant differences between the DNA methyltransferases expression in MM patients at different phases of the disease (possibly due to low patient counts), some of the outcomes were promising. Specifically, the expression level of DNMT3A was increased in patients with active MM (newly diagnosed patients and those in relapse) in both unsorted and sorted cell population compared to healthy controls and even to DNMT1 and DNMT3B expression profiles in MM patients. The global DNA methylation had a similar trend towards higher levels in active MM and lower level of methylation in remisson phase MM, even below the reported physiological value of global cytosine methylation ${ }^{17}$.

Cell sorting may be a limiting factor that interferes with the use of cell samples for further analyses, for example due to the inability to obtain sufficient amount of nucleic acids for the desired expression assays. It is known that only $20 \%$ of bone marrow aspirates ensure a sufficient number of plasma cells when sorted with a set of antibodies ${ }^{25}$. In our study, equal changes in the expression profile of DNMTs were found in both sorted and unsorted cell populations.

\section{CONCLUSIONS}

Increased expression of the DNMT3A gene could highlight the DNMT3A as a potential marker of multiple myeloma disease progression. The global DNA methylation in our MM cohort had lower overall levels in comparison with reported physiological values. We did not detect any significant correlation between the level of global methylation nor the expression of DNMT1, DNMT3A and DNMT3B in the unsorted cell population and the clinical stage of MM patients.

\section{ABBREVIATIONS}

BM: Bone marrow; CML: Chronic myelogenous leukemia, DNA methyltransferase 1; DNMT3A: DNA methyltransferase 3A; DNMT3B: DNA methyltransferase 3B; ISS - International Scoring System; MDS: Myelodysplastic syndrome, MGUS: Monoclonal gammopathy of undetermined significance; MM: Multiple myeloma; ns: not significant; R-ISS - Revised International Scoring System; 5-mC: 5-methylcytosine.

Acknowledgements: This study was funded in part by NV18-03-00500 from the Ministry of Health of the Czech Republic, the European Regional Development Fund Project ENOCH (No. CZ.02.1.01/0.0/0.0/16_019/00008 68) and LF_2021_005 from Palacky University Olomouc. The authors would like to acknowledge Kateřina Ćížková for statistical analysis. The authors would also like to 
thank the Department of Hemato-Oncology, University Hospital Olomouc, especially Dr. Petra Krhovska for providing patients' clinical data.

Author contributions: PL: conceptualization, methodology, software, formal analysis, investigation, data curation, writing-original draft preparation; DWD: methodology, formal analysis, investigation, data curation, writing-original draft preparation; PF: methodology, writing-original draft preparation; KO: methodology; IU: methodology; JM: writing-original draft preparation; ZK: draft revision; KST: conceptualization, methodology, writing-original draft preparation, supervision, project administration. All authors have read and agreed to the published version of the manuscript.

Conflicts of interest statement: None declared.

\section{REFERENCES}

1. Rollig C, Illmer T. The efficacy of arsenic trioxide for the treatment of relapsed and refractory multiple myeloma: a systematic review. Cancer Treat Rev 2009;35(5):425-30.

2. Kyle RA, Therneau TM, Rajkumar SV, Offord JR, Larson DR, Plevak MF, Melton LJ 3rd. A long-term study of prognosis in monoclonal gammopathy of undetermined significance. $\mathrm{N}$ Engl J Med 2002;346(8):564-9.

3. Bringhen $S$, Mateos MV, Zweegman S, Larocca A, Falcone AP, Orio A, Rossi D, Cavalli M, Wijermans P, Ria R, Offidani M, Lahuerta JJ, Liberati AM, Mina R, Callea V, Schaafsma M, Cerrato C, Marasca R, Franceschini L, Evangelista A, Teruel Al, van der Holt B, Montefusco V, Ciccone G, Boccadoro M, San Miguel J, Sonneveld P, Palumbo A. Age and organ damage correlate with poor survival in myeloma patients: meta-analysis of 1435 individual patient data from 4 randomized trials. Haematologica 2013;98(6):980-7.

4. Castaneda O, Baz R. Multiple Myeloma Genomics - A Concise Review. Acta Med Acad 2019;48(1):57-67.

5. Gay F, Larocca A, Wijermans P, Cavallo F, Rossi D, Schaafsma R, Genuardi M, Romano A, Liberati AM, Siniscalchi A, Petrucci MT, Nozzoli C, Patriarca F, Offidani M, Ria R, Omedè $P$, Bruno B, Passera $R$, Musto $P$, Boccadoro $M$, Sonneveld $P$, Palumbo A. Complete response correlates with long-term progression-free and overall survival in elderly myeloma treated with novel agents: analysis of 1175 patients. Blood 2011;117(11):3025-31.

6. Kumar SK, Dispenzieri A, Lacy MQ, Gertz MA, Buadi FK, Pandey S Kapoor P, Dingli D, Hayman SR, Leung N, Lust J, McCurdy A, Russell SJ, Zeldenrust SR, Kyle RA, Rajkumar SV. Continued improvement in survival in multiple myeloma: changes in early mortality and outcomes in older patients. Leukemia 2014;28(5):1122-8.

7. Neuse CJ, Lomas OC, Schliemann C, Shen YJ, Manier S, Bustoros M, Ghobrial IM. Genome instability in multiple myeloma. Leukemia 2020;34(11):2887-97.

8. Sonneveld P, Goldschmidt H, Rosiñol L, Bladé J, Lahuerta JJ, Cavo M Tacchetti P, Zamagni E, Attal M, Lokhorst HM, Desai A, Cakana A, Liu $\mathrm{K}$, van de Velde $\mathrm{H}$, Esseltine DL, Moreau P. Bortezomib-based versus nonbortezomib-based induction treatment before autologous stem-cell transplantation in patients with previously untreated mul- tiple myeloma: a meta-analysis of phase III randomized, controlled trials. J Clin Oncol 2013;31(26):3279-87.

9. Diagnostika a léčba mnohočetného myelomu. Transfuze a hematologie dnes 2018: Suplement 1. (in Czech)

10. Manier S, Salem KZ, Park J, Landau DA, Getz G, Ghobrial IM. Genomic complexity of multiple myeloma and its clinical implications. Nat Rev Clin Oncol 2017;14(2):100-13.

11. Choudhury SR, Ashby C, Tytarenko R, Bauer M, Wang Y, Deshpande S, Den J, Schinke C, Zangari M, Thanendrarajan S, Davies FE, van Rhee F, Morgan GJ, Walker BA. The functional epigenetic landscape of aberrant gene expression in molecular subgroups of newly diagnosed multiple myeloma. J Hematol Oncol 2020;13(1):108.

12. Chim CS, Kwong YL, Liang R. Gene hypermethylation in multiple myeloma: lessons from a cancer pathway approach. Clin Lymphoma Myeloma 2008;8(6):331-9.

13. Ehrlich M, Lacey M. DNA methylation and differentiation: silencing, upregulation and modulation of gene expression. Epigenomics 2013;5(5):553-68

14. Akhavan-Niaki $H$, Samadani AA. DNA methylation and cancer development: molecular mechanism. Cell Biochem Biophys 2013;67(2):501-13.

15. Dimopoulos K, Gimsing P, Grønbæk K. The role of epigenetics in the biology of multiple myeloma. Blood Cancer J 2014;4(5):e207.

16. Rajkumar SV, Dimopoulos MA, Palumbo A, Blade J, Merlini G, Mateos MV, Kumar S, Hillengass J, Kastritis E, Richardson P, Landgren O, Paiva B, Dispenzieri A, Weiss B, LeLeu X, Zweegman S, Lonial S, Rosinol L, Zamagni E, Jagannath S, Sezer O, Kristinsson SY, Caers J, Usmani SZ, Lahuerta JJ, Johnsen HE, Beksac M, Cavo M, Goldschmidt H, Terpos E, Kyle RA, Anderson KC, Durie BG, Miguel JF. International Myeloma Working Group updated criteria for the diagnosis of multiple myeloma. Lancet Oncol 2014;15(12):e538-48.

17. Breiling A, Lyko F. Epigenetic regulatory functions of DNA modifications: 5-methylcytosine and beyond. Epigenetics Chromatin 2015;8:24.

18. Wong KK, Lawrie CH, Green TM. Oncogenic Roles and Inhibitors of DNMT1, DNMT3A, and DNMT3B in Acute Myeloid Leukaemia. Biomark Insights 2019;14:1177271919846454.

19. Alzrigat $M$, Párraga $A A$, Jernberg-Wiklund $H$. Epigenetics in multiple myeloma: From mechanisms to therapy. Semin Cancer Biol 2018;51:101-15.

20. Heuck CJ, Mehta J, Bhagat T, Gundabolu K, Yu Y, Khan S, Chrysofakis G, Schinke C, Tariman J, Vickrey E, Pulliam N, Nischal S, Zhou L, Bhattacharyya S, Meagher R, Hu C, Maqbool S, Suzuki M, Parekh S, Reu F, Steidl U, Greally J, Verma A, Singhal SB. Myeloma is characterized by stage-specific alterations in DNA methylation that occur early during myelomagenesis. J Immunol 2013;190(6):2966-75.

21. Ehrlich M. DNA methylation in cancer: too much, but also too little. Oncogene 2002;21(35):5400-13.

22. Ecsedi SI, Hernandez-Vargas H, Lima SC, Herceg Z, Adany R, Balazs M. Transposable hypomethylation is associated with metastatic capacity of primary melanomas. Int J Clin Exp Pathol 2013;6(12):2943-8.

23. Wedge E, Hansen JW, Garde C, Asmar F, Tholstrup D, Kristensen SS, Munch-Petersen HD, Ralfkiaer E, Brown P, Grønbaek K, Kristensen LS. Global hypomethylation is an independent prognostic factor in diffuse large B cell lymphoma. Am J Hematol 2017;92(7):689-94.

24. Moreaux J, Bruyer A, Veyrune JL, Goldschmidt H, Hose D, Klein B. DNA methylation score is predictive of myeloma cell sensitivity to 5-azacitidine. Br J Haematol 2014;164(4):613-6.

25. Potácová A, Stossová J, Buresová I, Kovárová L, Almási M, Penka M, Hájek R. Sample processing and methodological pitfalls in multiple myeloma research. Klin Onkol 2011;24 Suppl:S18-23. 